\title{
NUMERICAL STUDY ON DYNAMIC RESPONSE OF SUBMERGED FLOATING BREAKWATER WITH IMPERMEABLE MOORING PLATE
}

\author{
Wei PENG ${ }^{1}$, Kwang-Ho LEE ${ }^{2}$ and Norimi MIZUTANI 3 \\ ${ }^{1}$ Student Member of JSCE, M. Eng., Dept. of Civil Engineering, Nagoya University \\ (Furo-cho, Chikusa-ku, Nagoya, 464-8603, Japan) \\ ${ }^{2}$ Member of JSCE, Dr. of Eng., Associate Professor, Dept. of Civil Engineering, Nagoya University \\ (Furo-cho, Chikusa-ku, Nagoya, 464-8603, Japan) \\ ${ }^{3}$ Member of JSCE, Dr. of Eng., Professor, Dept. of Civil Engineering, Nagoya University \\ (Furo-cho, Chikusa-ku, Nagoya, 464-8603, Japan)
}

\begin{abstract}
浮防波堤の有効性を検討するために適用されてきた従来の数值計算手法は微小変位の仮定に基づくポ テンシャル理論が主に用いられてきたが，浮体の動的波浪応答や波浪制御面で重要となる隅角部での渦の 発生や砕波などの現象を直接反映させることは困難であった。本研究では, 波浪制御構造物の付加機能と して, 波エネルギーの回収システムを検討するために提案された傾斜板支持式の浮防波堤を対象とし，そ の動的解析を実現するためにNavier-Stokes Solverに基づく計算手法を開発した。この計算手法は, 従来のデ カルト格子上で任意形状の不透過境界を有寸る物体と流体の連成解析が可能なIB法を適用し, 移動構造物 の境界面の追跡が容易である. 数値計算結果は浮体の運動振幅やそれに伴う浮体前後の水面変動を良好に 再現可能であることを明らかにした。
\end{abstract}

Key Words : Floating breakwater, Navier-Stokes solver, Immersed boundary method, numerical wave tank, impermeable mooring plate

\section{INTRODUCTION}

Floating breakwaters, as a promising alternative solution to traditional gravity-type breakwaters, have gained more and more attentions due to many advantages, e.g. eco-friendliness, low construction cost, convenience of transportation and installation. Furthermore, with a wide application in the coastal and ocean engineering, the dynamics of floating breakwaters, including the response of the structure such as sway, heave and roll, has been a noteworthy research topic due to their importance in designing the structures and estimating the effects of them on incident waves.

Over the years, many studies have been undertaken to investigate the performances of different types of floating breakwaters, both experimentally and numerically, and abundant results have been accumulated. The earlier work on the dynamics of floating structures largely depends on the potential theory based on the assumptions of non-viscous and irrotational flow. For instance, Lee and $\mathrm{Cho}^{1)}$ proposed a numerical model based on an element-free Galerkin method (EFGM) to simulate the wave interactions with a slackly moored pontoon-type floating breakwater. However, these kinds of models might be faced with two difficulties in modeling the wave-structure problems. The first issue is the simulation of large-scale motions of floating body. The other difficulty is to reproduce the rotational motion of floating body and vortex generation around the structures. Mizutani et al.2) coupled the Fractional Area Volume Obstacle Representation (FAVOR) method with the volume of fluid (VOF) method, and applied the proposed model to investigate the dynamics of the tension-moored floating breakwaters. Nevertheless, the difficulty of fully satisfying the mass conservation over the movable solid boundary and the high computational cost of reconstructing the imposed boundary strongly limit the application of the FAVOR method. More recently, an Immersed Boundary (IB) method based numerical wave tank was presented by Lee and Mizutani ${ }^{3), 4)}$ to simulate the moving interface of complex geometry on an orthogonal Cartesian grid system. Additional 


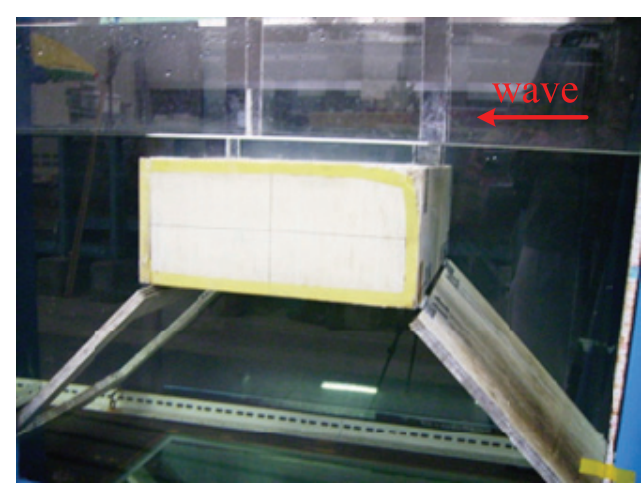

Fig. 1 Side view of the floating breakwater set up

investigations by Lee et al.5) and Peng et al.6) revealed that IB method can successfully simulate the dynamic behavior of the moored tension leg floating body with both vertical and inclined mooring systems.

Although various methodologies have been applied to examine the interactions between waves and floating bodies, very little research had been conducted in assessing the effects of the mooring system using impermeable plates, which may help in attenuating the wave energy by promoting wave breaking on the floating body. For example, Watanabe et al. ${ }^{7)}$ discussed the possibility of a new wave energy converter system making use of a floating breakwater with the impermeable mooring plate at the offshore side and permeable mooring plate at the onshore side as shown in Fig. 1.

The main purpose of this study is to investigate the applicability and validity of the numerical model proposed by Lee et al.3),4) in simulating the dynamics of a submerged floating breakwater with impermeable mooring plate. Another objective is to attempt to analyze the performance of the newly developed wave energy converter by Watanabe et al. ${ }^{7)}$ numerically. In the following sections, the numerical model proposed by Lee et al. ${ }^{3), 4)}$ will be briefly introduced. Then, mechanical model will be established among water waves, floating body and mooring plates. Three freedoms of floating breakwater motions are considered as sway, heave and roll. Finally, the experimental results are utilized to validate the numerical model in terms of free surface profiles, motions of floating body and water particle velocity fields.

\section{NUMERIAL MODEL}

\section{(1) Governing equations}

A 2-D numerical wave tank was utilized to study the wave-structure interactions in a Cartesian domain $\Omega$, as illustrated in Fig. 2. The flow of an

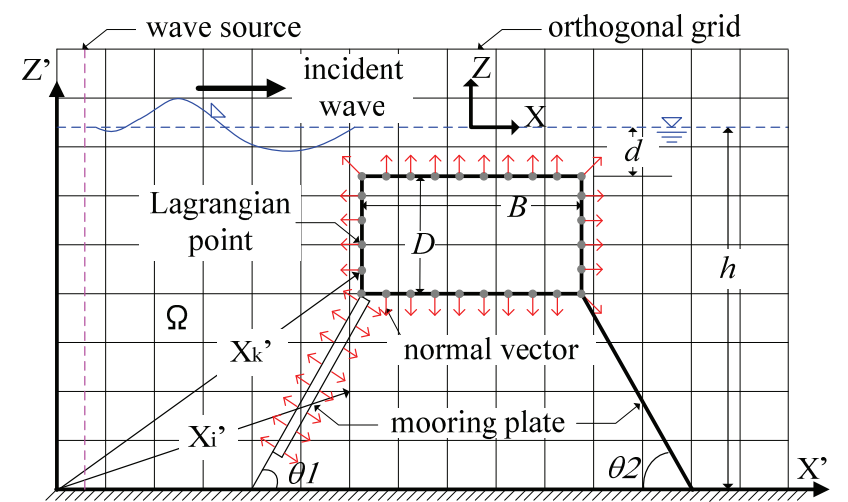

Fig. 2 Schematic illustration of computational domain

incompressible viscous fluid is governed by the modified Navier-Stokes equations:

$$
\begin{aligned}
\frac{D u_{i}}{D t}=- & \frac{1}{\rho} \frac{\partial p}{\partial x_{i}}+2 v \frac{\partial D_{i j}}{\partial x_{j}}-\frac{2 v}{3} \frac{\partial Q}{\partial x_{i}} \\
& -g_{i}-\mu_{i} \delta_{i 2}+L_{i}
\end{aligned}
$$

and the continuity equation:

$$
\frac{\partial u_{i}}{\partial x_{i}}=Q
$$

where $x_{i}$ donates the $x$ or the $z$ orthogonal Cartesian coordinate, $u_{i}$ is the velocity component $(u, w)$ in the $i$ direction, $p$ is pressure, $\rho$ is the fluid density, $t$ is time, $g$ is the acceleration due to gravity, $v$ is the kinematic viscosity coefficient of the water, $\gamma$ is a wave dissipation factor, which is equal to zero except for the sponge zones, $D_{i j}$ is the velocity stress tensor, and $Q$ is the source term at the source position $x=x_{s}, Q=q(z, t) / \Delta x_{s}$ where $q$ is the flux density and $\Delta x_{s}$ is the grid width at the source position. $L_{i}$, in the RHS of Eq. (1), is the Eulerian force $^{8)}$ in the $i$ direction, which represents the effect of solid domain on the flow domain, determined by

$$
L_{i}=\int_{\Omega} \widetilde{L}_{k i} \delta\left(x_{i}-x_{k}\right) d x_{k}
$$

where $\widetilde{L}_{k i}$ is the force density at the Lagrangian points $x_{k}$, and $\delta\left(x_{i}-x_{k}\right)$ is a Dirac delta function. Furthermore, the advection equation of VOF function, $F$, is solved to capture the free water surface, as follows:

$$
\frac{\partial F}{\partial t}+\frac{\partial\left(u_{i} F\right)}{\partial x_{i}}=F Q
$$

\section{(2) Numerical implementation of the model}

The two-step projection method proposed by Chorin ${ }^{9), 10)}$ is applied to solve the governing equations. The governing equations are discretized using the finite difference method based on the orthogonal Cartesian grid. All the scalar quantities including pressure $p$ and the VOF function $F$ are defined at the center of each rectangular cell, 


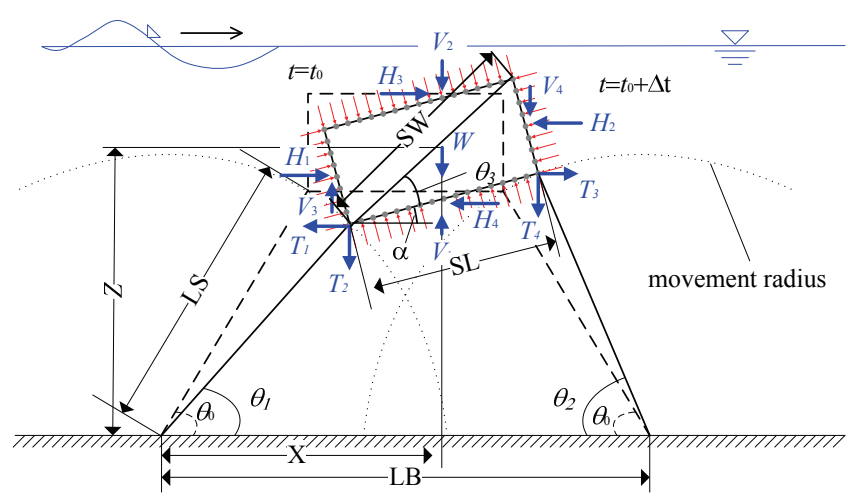

Fig. 3 Calculation of the floating body dynamics

whereas the vector variables are defined at the cell faces. Such an arrangement makes the gird suitable for a control volume discretization. In the framework of two-step projection method, firstly, the velocity is advanced explicitly to the intermediate velocity $\tilde{u}_{i}$ instead of $u_{i}^{n+1}$ without considering the pressure as:

$$
\begin{aligned}
\frac{\tilde{u}_{i}-u_{i}^{n}}{\Delta t}= & -u_{j} \frac{\partial u_{i}}{\partial x_{j}}+2 v\left(\frac{\partial D_{i j}}{\partial x_{j}}\right) \\
& \left.-\frac{2 v}{3} \frac{\partial Q}{\partial x_{i}}-g_{i}-m_{j} \delta_{j 2}+L_{i}\right]^{n}
\end{aligned}
$$

where the superscript represents the time level. The advection terms are advanced by the third-order Kawamura-Kuwahara (K-K) scheme $^{11}$ and the remaining terms are advanced using the second-order central difference approximation.

In the correction step, the intermediate velocity is projected onto a divergence free field to obtain the correct velocity, $u_{i}^{n+1}$, at the next time-level as follows:

$$
\begin{gathered}
\frac{u_{i}^{n+1}-\tilde{u}_{i}}{\Delta t}=-\frac{1}{\rho^{n}} \frac{\partial p^{n+1}}{\partial x_{i}} \\
\frac{\partial u_{i}^{n+1}}{\partial x_{i}}=0
\end{gathered}
$$

Combining Eq. (6) and Eq. (7), the Poisson Pressure Equation (PPE) for $p^{n+1}$ can be produced as:

$$
\frac{\partial}{\partial x_{i}}\left(\frac{1}{\rho^{n}} \frac{\partial p^{n+1}}{\partial x_{i}}\right)=\frac{1}{\Delta t} \frac{\partial \tilde{u}_{i}}{\partial x_{i}}
$$

Using Eq. (8), the pressure in each cell can be advanced to time-level $\mathrm{n}+1$, and the velocity can be updated using Eq. (6).

\section{(3) Determination of the Eulerian force}

It is noted that the forcing term $L_{i}$ is added to the


(B)

Fig. 4 Dynamics of the mooring plates: (A) offshore impermeable plate; (B) onshore permeable plate.

momentum equation to represent the embedded solid boundary in the IB method, which is originally introduced by Peskin ${ }^{12)}$. The imposed force components must be determined before the solution of the momentum equation. In the present model, the boundary of obstacle is replaced with a set of discrete control points $x_{k}$, referred to as Lagrangian points. Firstly, the force density $\widetilde{L}_{k i}$ in Eq. (3) is computed over these points, and then it is distributed to the nearby Cartesian grid points as Eulerian force by a certain distribution function.

In the first step, the PVM method ${ }^{8)}$ is applied to calculate the added forcing term explicitly. Based on the momentum equation, the forcing term is taken apart as acceleration forcing, inertial forcing, viscous forcing and pressure forcing. Then, a well-discretized Dirac delta function ${ }^{13)}$ is used to link force density over Lagrangian points to the Eulerian grids. Please refer to Lima E Silva et al. $\left.{ }^{8}\right)$ and Lee and Mizutani ${ }^{3), 4}$ ) for detailed numerical scheme of determining the force term.

\section{(4) Dynamics of the floating breakwater system}

The dynamic properties of the submerged floating breakwater due to its interaction with waves and mooring plates are formulated, as shown in Fig. 3 . The wave forces acting on the surfaces of the breakwater $H_{1} \sim H_{4}$ and $V_{l} \sim V_{4}$ can be calculated by integrating the pressures on the corresponding surface. For the floating body, considering the moments acting on the centre of gravity, resultant horizontal and vertical force acting on the body, the following equations can be derived:

$$
\begin{gathered}
\sum M_{c g . x}+\sum M_{c g . z}+\sum M_{c g . T}=-J_{F B} \alpha_{F B} \\
m \alpha_{x}=H_{1}+H_{3}-H_{2}-H_{4}-T_{1}+T_{3} \\
-m \alpha_{Z}=V_{2}+V_{4}+W-V_{1}-V_{3}+T_{2}+T_{4}
\end{gathered}
$$

where $\sum M_{c g . x}, \quad \sum M_{c g . z}, \quad \sum M_{c g . T}$ represent the summation of moment governed by the horizontal 



Fig. 5 Numerical model results of water particle velocity $(\mathrm{cm} / \mathrm{s})$ field around the floating breakwater $\left(T_{i}=1.6 \mathrm{~s} ; H_{i}=13.32 \mathrm{~cm} ; h=63 \mathrm{~cm}\right)$

wave forces, vertical wave forces and the mooring forces respectively, $J_{F B}$ is the mass moment of inertia of the floating body, $\alpha_{F B}, \alpha_{x}, \alpha_{z}$ are the accelerations of angle $\alpha$, horizontal direction and vertical direction respectively; $m$ is the mass of the floating body.

Similarly, the dynamics of mooring plates are illustrated in Fig. 4. Considering the moments acting on the anchored points at the bottom of wave tank, the following equations can be derived:

$$
\begin{aligned}
& \sum M_{B 1}=-J_{B 1} \alpha_{B 1} \\
& \sum M_{B 2}=J_{B 2} \alpha_{B 2}
\end{aligned}
$$

where $\sum M_{B 1}$ and $\sum M_{B 2}$ represent the summation of moment acting on the mooring plate of onshore and offshore side, respectively, $J_{B 1}$ and $J_{B 2}$ is the mass moment of inertia of the mooring plates, $\alpha_{B 1}$ and $\alpha_{B 2}$ are the accelerations of angle $\theta_{1}$ and $\theta_{2}$, respectively.

Considering the constant length of mooring plates, four additional equations can be derived from the geometry in Fig. 3 as:

$$
\begin{gathered}
L S^{2}-\left(L B-L S \cos \theta_{1}-S L \cos \alpha\right)^{2} \\
=\left(L S \sin \theta_{1}+S L \sin \alpha\right)^{2} \\
\sin \theta_{1}=\frac{Z_{c . g}-S W \sin \left(\theta_{3}+\alpha\right) / 2}{L S} \\
\sin \theta_{2}=\frac{L S \sin \theta_{1}+S L \sin \alpha}{L S} \\
\cos \theta_{1}=\frac{X_{c . g}-S W \cos \left(\theta_{3}+\alpha\right) / 2}{L S}
\end{gathered}
$$

By solving above five equations (Eq. (9) Eq. (17)) simultaneously, we can calculate the unknown parameters $\alpha_{F B}, \alpha_{x}, \alpha_{z}, \alpha_{B 1}, \alpha_{B 2}, T_{1}, T_{2}, T_{3}$ and $T_{4}$.

Table 1 Cases of experiments

\begin{tabular}{c|c|c}
\hline $\begin{array}{c}\text { Water depth } \\
h(\mathrm{~cm})\end{array}$ & $\begin{array}{c}\text { Wave period } \\
T_{i}(\mathrm{~s})\end{array}$ & $\begin{array}{c}\text { Wave steepness } \\
H_{i} / L_{i}\end{array}$ \\
\hline & $\begin{array}{c}1.0,1.2,1.4, \\
1.6,1.8\end{array}$ & $0.02,0.03,0.04$ \\
$57,60,63$ & $\begin{array}{c}0.9 \\
\end{array}$ & \\
\hline
\end{tabular}

Finally, the sway, heave and roll displacements of floating breakwater are estimated using $\alpha_{F B}, \alpha_{x}$ and $\alpha_{z}$ values and the corresponding positions of mooring plates can be obtained.

\section{RESULTS AND DISCUSSIONS}

A set of experiments were conducted in the two-dimensional wave tank at the Coastal and Ocean Engineering Laboratory, Dept. of Civil Engineering, Nagoya Univ., Japan. The wave tank is $30 \mathrm{~m}$ long, $0.7 \mathrm{~m}$ wide and $0.9 \mathrm{~m}$ deep, in which periodic waves were generated by a piston-type paddle at one end of the tank. In the experiments, a rectangular shaped pontoon type submerged floating breakwater measuring $0.4 \mathrm{~m}$ in length, $0.69 \mathrm{~m}$ in width, $0.18 \mathrm{~m}$ in height, and $8.89 \mathrm{kgf}$ in weight was used. This floating breakwater is moored by the impermeable plates (see Fig. 1). All experimental tests were carried out for regular waves and summarized in Table 1. In this study, a detail investigation for one case is presented to investigate the performance of the developed model: wave period $T_{i}=1.6$ seconds; wave height $H_{i}=0.1332 \mathrm{~m}$; still water depth $h=0.63 \mathrm{~m}$; submergence depth, which is the distance from the still water level to the top surface of floating breakwater $d=0.03 \mathrm{~m}$; inclined angle $\theta_{0}=45^{\circ}$; wave steepness $H_{i} / L_{i}=0.04$. For other cases, general comparisons are carried out to demonstrate the extensive applicability and practical significance. In the computation, a uniform grid system with $\Delta x=\Delta z=0.01 \mathrm{~m}$ and the time interval of $0.001 \mathrm{~s}$ was employed to discretize the problem spatially and temporally.

Figure 5 presents the evolution of the water particle velocities and the free water surface profiles around the submerged semicircular cylinder during one wave cycle with the time interval of $0.4 \mathrm{~s}$. As seen in figure, we can clearly observed that the significant effect of impermeable mooring plate on 


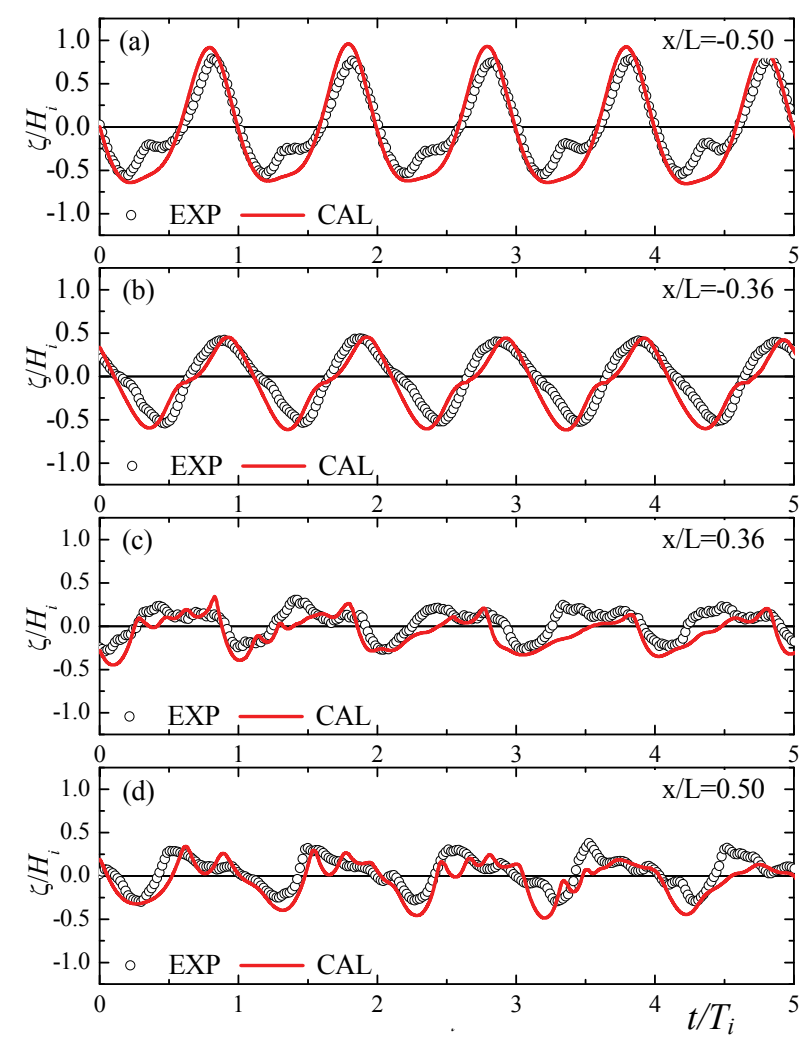

Fig. 6 Comparisons between numerical and experimental results of dimensionless water surface profiles $\left(T_{i}=1.6 \mathrm{~s} ; H_{i}=13.32 \mathrm{~cm} ; h=63 \mathrm{~cm}\right)$

wave fields and is well reproduced. The process of wave propagation over the submerged floating body can be also traced in this figure. From Fig. 5(a), the regular wave is approaching the obstacle and then breaks over the top surface of floating body as shown in Fig 5(b) and (c). Vortexes are also observed under and behind the floating body in Fig. 5(d), which cannot be simulated using potential theory. Another noteworthy feature is the convenience of capturing the corresponding positions of the breakwater, which show an oscillation due to the interaction with waves.

Fig. 6 presents a comparison between the numerical results obtained using the present model and the measured data for the free-surface evolutions at four stations for five wave cycles. In general, a favorable agreement is observed between the measurements and estimations. At the offshore side, Fig. 6(a) and Fig. 6(b), the proposed model performs well in simulating the wave height and phase although there is small disparity between the shape of curves of experimental and numerical results. At the onshore side, Fig. 6(c) and Fig. 6(d), the time variation of water surface profiles indicates higher harmonic generation in the reformed area after the wave breaking due to the interaction with the submerged floating breakwater.

In addition, by applying the frequency domain

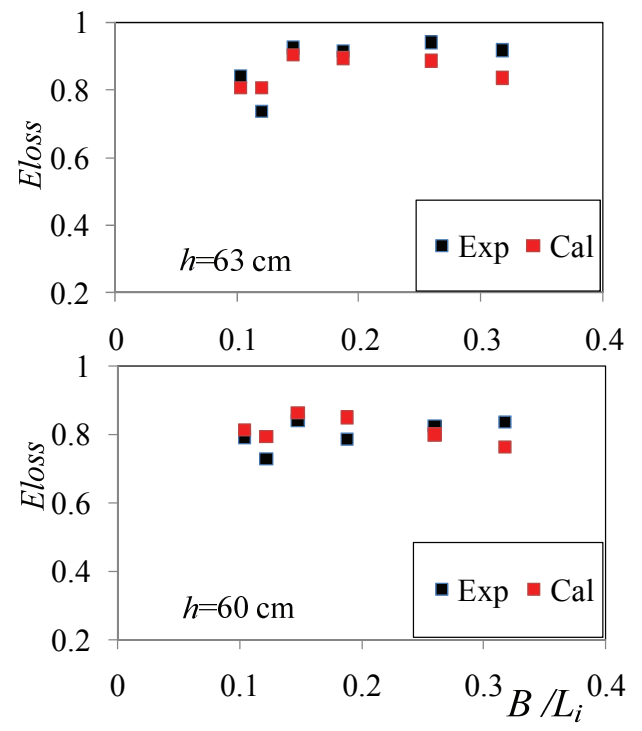

Fig. 7 Comparisons between experimental results and simulations of wave energy loss for different water depths $\left(H_{i} / L_{i}=0.04\right)$
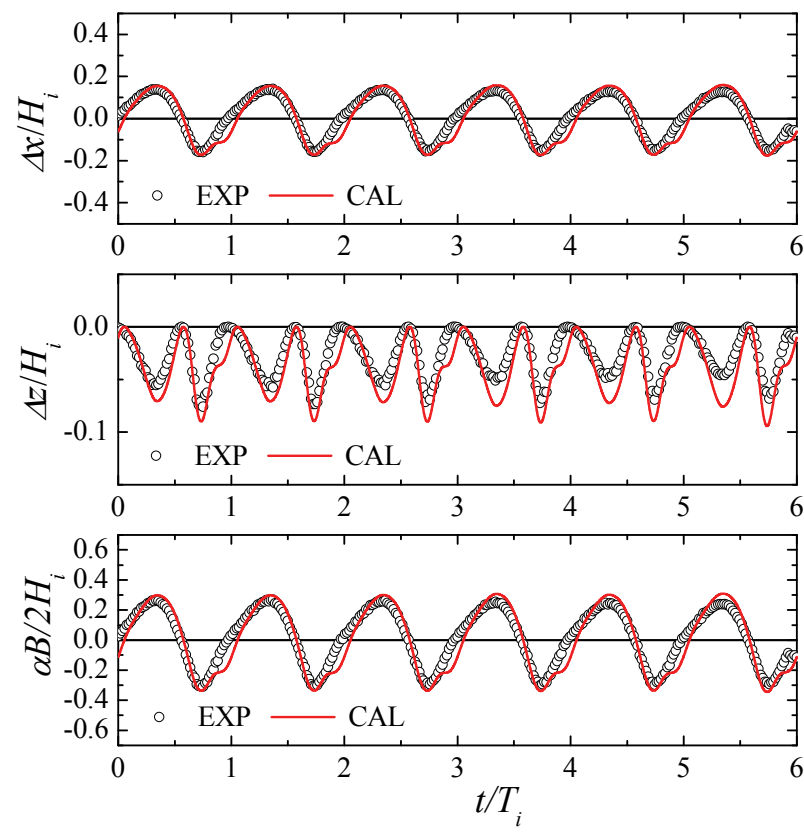

Fig. 8 Comparisons between numeircal and experimental results of displacmenets of floaitng body

$\left(T_{i}=1.6 \mathrm{~s} ; H_{i}=13.32 \mathrm{~cm} ; h=63 \mathrm{~cm}\right)$

analysis to the wave histories of wave gauges, the coefficients of reflection $\left(K_{r}\right)$ and transmission $\left(K_{t}\right)$ can be computed. And then, the dissipation rate (Eloss) of incident wave energy by the structure is formulated as follows:

$$
\text { Eloss }=\sqrt{1-K_{r}^{2}-K_{t}^{2}}
$$

Fig. 7 presents the comparisons between experimental data and numerical results of the wave energy loss for different water depths with the constant wave steepness value of 0.04 . In general, the predictions agree fairly with the experimental 
results. Furthermore, it is observed that the floating breakwater performs better in controlling wave energy for the cases with shorter wave periods.

Numerical results of sway, heave and roll motions of floating body are compared with the experimental data as function of dimensionless time in Fig. 8. In attenuating the wave energy, the roll motion plays an important role by causing the top surface of floating breakwater inclined and then acts as a wave absorbing slope of the incoming wave. Fig. 8 presents a good agreement in predicting the phase and amplitude of the roll and sway displacements except the heave motion. Considering the inevitable measurement errors during experiments and its magnitude, the assessment of heave movement is also acceptable. Thus, the developed model is validated to be reliable dynamic simulator in modeling the interactions between water waves and the submerged floating breakwater.

\section{CONCLUSION}

The study focuses on the numerical simulation of the dynamic response of a submerged pontoon-type floating breakwater with mooring plates system, using the IB method and VOF method. The impermeable mooring plate was employed at the offshore side in order to enhance wave breaking. In the course of analysis, we have the demonstrated that the developed model is powerful in reproducing the effects of impermeable mooring plate on the water particle velocity around the floating breakwater. Also, the water surface displacements in front and at the back of the floating body were estimated numerically. The validity and applicability of the developed model is well supported by the comparisons of estimated values and experimental measurements in evaluating water surface profiles. More importantly, the motions of floating breakwater are assessed considering the interactions among water waves, floating body and impermeable mooring plate. The favorable agreement between numerical estimation and experimental data proves the capacity of proposed model in mimicking the dynamics of a submerged rectangular floating breakwater anchored to the bottom using plates. As mentioned in section 1, the same configuration as this paper has been applied in the wave energy converter system in the study of Watanabe et al. ${ }^{7}$. Therefore, we are updating the developed numerical model to extend its applicability to the simulation of electricity power output coupling the generator and the results will be reported in the near future.

\section{REFERENCES}

1) Lee, J. and W. Cho: Hydrodynamic analysis of wave interactions with a moored floating breakwater using the element-free Galerkin method, Canadian Journal of Civil Engineering, Vol. 30, No 4, pp. 720-733, 2003.

2) Mizutani, N., M.A. Rahman, D.S. Hur and H. Shimabukuro: VOF simulation for dynamic behavior of submerged floating breakwater and wave deformation considering finite displacement, Annual Journal of the Costal Engineering, JSCE, Vol. 51, pp. 701-705, 2004. (in Japanese)

3) Lee, K.-H. and N. Mizutani: Numerical wave flume with immersed boundary method and its applicability in wave fields simulation around a horizontal circular cylinder, Annual Journal of Coastal Engineering, JSCE, Vol. 54, pp. 821-825, 2007. (in Japanese)

4) Lee, K.-H. and N. Mizutani: A numerical tank using direct-forcing immersed boundary method and its application to wave force on a horizontal cylinder, Costal Engineering Journal, Vol. 51, No. 1, pp. 27-48, 2009.

5) Lee, K.-H., N. Mizutani and M. Goto: Numerical simulation of dynamic behavior of tension leg floating body using IB method, Annual Journal of Coastal Engineering, JSCE, Vol.55, pp.891-895, 2008. (in Japanese)

6) Peng W., Lee, K.-H and N. Mizutani: Numerical study on dynamics response of tension-moored floating structure using IB-VOF method, Proceedings of Costal Engineering, JSCE, Vol. 1, 2010.

7) Y. Watanabe, Peng W. and N. Mizutani: Experimental sutyd on wave energy converter system using floating breakwater, Annual Journal of Civil Engineering in the Ocean, JSCE, Vol. 26, pp. 513-518, 2010. (in Japanese)

8) Lima e Silva, A. L. F., A. Silveria-Neto and J. J. R. Damasceno: Numerical simulation of two dimensional flows over a circular cylinder using the immersed boundary method, Journal of Computational Physics, Vol. 351, pp. 351-370, 2003.

9) Chorin, A. J.: Numerical solution of the Navier-Stokes equations, Math. Comp., Vol. 22, pp. 745-762, 1968.

10) Chorin, A. J.: On the convergence of discrete approximations to the Navier-Stokes equations, Math. Comp., Vol. 23, pp. 341-353, 1969.

11) Kawamura, T. and K. Kuwahara: Computation of high Reynolds number flow around a circular cylinder with surface roughness, AIAA Paper, pp. 84-340, 1984.

12) Peskin, C. S.: Numerical analysis of blood flow in the heart, Journal of Computational Physics, Vol. 25, pp. 220-252, 1977.

13) Griffith, B.E. and C. S. Peskin: On the order of accuracy of the immersed boundary method: Higher order convergence rates for sufficiently smooth problems, Journal of Computational Physics, Vol. 208, pp. 75-105, 2005.

(April 4, 2011) 